\title{
La reconstrucción de inmuebles de interés cultural. Del teatro de Sagunto al museo del Prado
}

Antonio Gayo Rubio, letrado de la Junta de Andalucia

\author{
"Estos, Fabio, jay dolor!, que ves ahora \\ campos de soledad, mustio collado, \\ fueron un tiempo Itálica famosa. \\ Aqui de Cipión la vencedora \\ colonia fue; por tierra derribado \\ yace el temido honor de la espantosa \\ muralla, y lastimosa \\ reliquia es solamente \\ de su invencible gente..."
}

(Canción a las ruinas de Itálica. Rodrigo Caro)

\section{INTRODUCCIÓN}

A través del presente comentario serán expuestos dos importantes pronunciamientos del Tribunal Supremo relativos al artículo 39. 2 de la Ley 16/1985, de 25 de junio, del patrimonio histórico artístico español (en adelante LPHE) sobre restauración de monumentos históricos, su conservación y disfrute.

Mediante las sentencias de 16 de octubre de 2000 y de 18 de diciembre de 2002, el Tribunal Supremo vino a establecer su doctrina acerca de la intensidad de las intervenciones en el patrimonio histórico, la cual fue sentada al resolver la controversia suscitada en dos conocidos casos entre los partidarios de la intangibilidad de inmuebles arruinados por el paso del tiempo y partidarios de reconstrucciones que no se ciñan necesariamente al edificio tal como fue concebido. El Tribunal Supremo precisó los límites legales establecidos en el precepto mencionado pero la realidad demuestra que en éste, como en muchos ámbitos del Derecho, no es posible avanzar soluciones generales y que conviene estar a las particularidades de cada caso concreto, pues no cabe duda de que desde la prohibición de la obra del teatro romano a la aprobación de las obras de ampliación del museo del Prado media una importante distancia conceptual desde el punto de vista arquitectónico, en la que se advierte un cambio en la concepción del patrimonio y en las posibilidades de intervención en el mismo. La doctrina establecida, no obstante, resulta sumamente valiosa pues delimita el ámbito dentro del cual pueden realizarse las intervenciones en los inmuebles de interés cultural.

El artículo 39 de la LPHE, tras ordenar a los poderes públicos que "procuren por todos los medios de la técnica la conservación, consolidación y mejora de los bienes declarados de interés cultural asi como de los bienes culturales incluidos en el Inventario General del artículo 26 de la Ley", concreta que "tratándose de bienes inmuebles, estas actuaciones han de ir encaminadas a su conservación, consolidación y rehabilitación y evitarán los intentos de reconstrucción, salvo cuando se utilicen partes originales de los mismos y pueda probarse su autenticidad". El artículo prevé que "si se añadiesen materiales o partes indispensables para su estabilidad o mantenimiento las adiciones deberán ser reconocibles y evitar las confusiones miméticas. Se impone que las restauraciones de los bienes respeten las aportaciones de todas las épocas existentes así como que la eliminación de alguna de ellas sólo se autorice con carácter excepcional y siempre que los elementos que traten de suprimirse supongan una evidente degradación del bien cuya eliminación fuere necesaria para permitir una mejor interpretación histórica del mismo. De las partes que se supriman debe quedar la debida documentación".

Expuesto el contenido del precepto procede referirse a las sentencias mencionadas.

\section{LA RECONSTRUCCIÓN DEL TEATRO ROMANO DE SAGUNTO}

La primera de ellas es la sentencia de la Sala de lo ContenciosoAdministrativo del Tribunal Supremo de 16 de octubre de 2000 que vino a confirmar que era contraria a Derecho la resolución de la Generalidad Valenciana de 1988 que aprobó el proyecto de restauración y rehabilitación del teatro Romano de Sagunto. El proceso fue iniciado por un particular en ejercicio de la acción pública en defensa del patrimonio histórico. La sentencia menciona un hecho muy importante como es el de que, varios años después de iniciado el proceso, la propia administración autonómica valenciana durante la tramitación del recurso de casación desistió del mismo con fundamento en un cambio en la legislación valenciana sobre patrimonio histórico y por considerar que el proyecto de restauración y rehabilitación consistía realmente en una obra que se asentaba sobre las ruinas de un teatro romano y las ocultaba, tratándose de una reconstrucción sobre las ruinas auténticas que constituía una infracción de los limites de la LPHE. Aunque el recurso siguió tramitándose a instancia del particular que inició el proceso, no cabe duda de que la postura de la propia administración que aprobó el proyecto reconociendo su ilegalidad era muy significativa. 
En sintesis considera la sentencia que las obras autorizadas no eran de restauración ni de consolidación sino de reconstrucción y que donde antes habia unas simples ruinas se ha venido a crear un teatro al modo de los romanos.

En el comentario a la sentencia del Tribunal Supremo sobre el teatro Romano de Sagunto, escrito por el catedrático Santiago Muñoz Machado y titulado La resurrección de las ruinas, y cuya lectura se recomienda desde aquí, se aclara una circunstancia importante que a su juicio no se recogió en la sentencia y que resultaba capital para decidir el asunto. Basándose en la literatura técnica existente sobre el tema habia que partir de la constatación de un importante hecho omitido en la sentencia como es el de que las ruinas del teatro Romano de Sagunto eran unas ruinas artificiales. 0 sea que en el teatro se confundian los restos romanos y originales -del tiempo del emperador Tiberio (14-37 d. de C.) según la sentencia- con otras aportaciones constructivas producidas a lo largo del tiempo hasta llegar a la actualidad, de las cuales unas serian reconstructivas y otras destructivas. Casi todas fueron ejecutadas a partir del siglo XIX de manera que había muy pocos vestigios romanos en el lugar. El pórtico superior y su graderío fueron demolidos por razones de táctica militar en 1811 en la guerra contra los franceses. Las gradas fueron restauradas entre los años 1955 y 1978. La sentencia, por tanto, se puede afirmar que se apoya sobre la premisa errónea de considerar que las ruinas del teatro eran originales. No obstante, no se puede reprochar a los magistrados que enjuiciaron el asunto tan importante equivocación pues, por una parte, en fase de recurso de casación las posibilidades de revisar la apreciación de las pruebas Ilevadas a cabo por la Sala de lo Contencioso-Administrativo del Tribunal Superior de Justicia de Valencia resultaban ya muy limitadas y, por otra, no se puede desconocer que la tarea de convencer al tribunal acerca de este hecho le correspondia a los profesionales a quienes concierne lograr la convicción del tribunal sobre los hechos, que son los letrados intervinientes en el proceso mediante la práctica de las pruebas que estimen oportunas, entre las que se encuentran las periciales.

No obstante, aunque la sentencia de 16 de octubre de 2000 parte de una apreciación equivocada de la realidad histórica de las ruinas no deja por ello de sentar una importante doctrina acerca de la intervención en los inmuebles de interés cultural con definición de sus limites positivos y negativos.

La sentencia centra la cuestión sobre la que resuelve advirtiendo con carácter previo que no le correspondía a la sala juzgar el proyecto desde un punto de vista cultural, artístico o arquitectónico, sino exclusivamente jurídico. En definitiva, aclara que la función del tribunal consiste en examinar si el proyecto es respetuoso con la opción política elegida por el legislador acerca de la intervención en los inmuebles de interés cultural.

Para no apartarse del único criterio jurídico que debía presidir la toma de su decisión, el tribunal explica que el contenido del artículo 39 de la LPHE es fruto de un debate parlamentario en el que han es- tado presentes las diversas corrientes académicas que existen acerca de la reconstrucción de los inmuebles de interés cultural, algunas de las cuales se remontan a la época renacentista. La sentencia expone que existen dos teorías predominantes en la materia representadas por una parte por aquellos que sólo autorizan intervenciones que traten de conseguir la unidad de estilo del monumento tal como fue concebido por sus artífices originarios y, por otra parte, la de los partidarios de la mínima intervención en el monumento para que sin incidir en los mismos reflejen el curso de la historia. Dichas teorías se han visto enriquecidas por otras posteriores que permiten ciertas intervenciones, bien para evitar su degradación o bien incluso para que el monumento recupere su imagen original. En este punto resulta interesante la relación de las teorias que se recogen en la obra de Muñoz Machado y en el auto del Tribunal Superior de Justicia de Valencia de 7 de abril de 2009 que declaró la imposibilidad legal de ejecutar la sentencia como se contará al final.

La sentencia alude asimismo a cartas y declaraciones internacionales que han reflejado unas u otras teorias como son la Carta Internacional de la Restauración de Atenas de 1931, la Carta de Venecia de la Restauración y Conservación de Monumentos de 1964, las cartas italianas del restauro o la Carta Europea del Patrimonio Arquitectónico de 1975. Si en algo vienen a coincidir la mayoria de ellas es en la recomendación de que se descarten los intentos de recomponer o reconstruir los monumentos antiguos, considerando aceptable tan sólo la anastilosis o recomposición de las partes originales existentes que se encuentren desmembradas, siempre que estén debidamente documentadas, pero excluyendo con carácter general la "recuperación" del estado original de la obra de arte. La carta italiana de 1972 en concreto es expresamente contraria a la integración ex novo de zonas con representación figurada o con la inserción de elementos determinantes para la figuratividad de la obra. Sólo en circunstancias verdaderamente excepcionales, como las de ciudades destruidas por las guerras, algunas declaraciones, como la de la muy castigada durante la Segunda Guerra Mundial ciudad de Dresde de 1982, admiten como principio la reconstrucción monumental del patrimonio arquitectónico.

Tras recordar asimismo que la opción elegida por el legislador se basa en el artículo 19 de la Ley de protección del tesoro artístico nacional, de 13 de mayo de 1933 y, por tanto, en nuestra tradición legislativa, se concluye que la ley de patrimonio se suma a la doctrina científica internacional de la restauración recogiendo las principales orientaciones de las conferencias internacionales sobre el patrimonio artístico y su estricta observancia.

\section{La doctrina que sienta el Tribunal Supremo acerca del artículo 39 de la LPHE es la de que por ley se ha consagrado el principio de evitar los intentos de reconstrucción de los inmuebles históricos de interés cultural}


En definitiva, la sentencia explica que el legislador, tras haber barajado diversas corrientes doctrinales, ha optado por una concreta, de manera que no resulta admisible sustraerse a los criterios legales sobre restauración de inmuebles de interés cultural para sustituirlos por otros criterios alternativos que, si bien pueden ser académicamente aceptables, serian de indole artístico, cultural o arquitectónico pero no legales. De hecho, insiste en que la reconstrucción puede asentarse sobre presupuestos metodológicamente admisibles sobre los que no le corresponde pronunciarse al tribunal pero que no pueden vulnerar los criterios normativos plasmados en el artículo 39. 2 de la LPHE.

La doctrina que sienta el Tribunal Supremo acerca del artículo 39 de la LPHE es la de que por ley se ha consagrado el principio de evitar los intentos de reconstrucción de los inmuebles históricos de interés cultural y la de que se permiten las operaciones de conservación, consolidación o rehabilitación. Ahora bien, en el supuesto -que la sentencia recalca que sería excepcional- de que hubiera de procederse a la reconstrucción, la misma habría de utilizar partes originales de probada autenticidad.

Una vez expuesta la doctrina del Tribunal Supremo acerca de la rehabilitación y reconstrucción de inmuebles de interés cultural que se encuentren -en palabras de la sentencia con cita expresa de Francisco de Quevedo- "si un tiempo fuertes, ya desmoronados" se concluye en la sentencia que en el proyecto de restauración y rehabilitación del teatro Romano de Sagunto se advirtió que lo que se iba a acometer en realidad era una operación de reconstrucción del teatro vedada por la ley pues no se iban a emplear piezas originales de probada autenticidad.

La reconstrucción tenía como finalidad restituir la unidad de la forma arquitectónica del espacio teatral y no podia ocultar la realidad de la intervención propuesta que, si bien era menor en la cávea, es radical en la escena, sobre cuyos restos actuales se levantaría nada menos que un completo, y en gran parte nuevo, edificio teatral.

La sentencia se basa, para llegar a tal conclusión, en la prueba practicada en la instancia ante el Tribunal Superior de Justicia de Valencia de las que resultan destacables las manifestaciones de los propios autores del proyecto y las opiniones de los técnicos de la administración. El tribunal se valió asimismo de un informe de la Real Academia de San Carlos e incluso de la poco empleada prueba de reconocimiento judicial que exige que el tribunal se desplace y examine por sí mismo algún lugar, objeto o persona porque se considere necesario para lograr su convicción (artículo 353 y ss. de la vigente Ley de enjuiciamiento civil 1/2000).

Con esta sentencia dictada en el año 2000 se confirmó la declaración de ilegalidad de un proyecto que databa del año 1988 aunque los avatares de la reconstrucción del teatro Romano de Sagunto no habrian de concluir hasta el año 2008. La ejecución de una sentencia que condenaba a la demolición entrañaba dificultades como la de determinar la manera de proceder contra la obra ejecutada sin afectar a elementos originales del teatro. Se planteó la creación de una comisión interdisciplinar que redactase un proyecto técnico de reversibilidad de las obras. En este tiempo se modificó la redacción del artículo 38. d) de la Ley 4/1998, de 11 de junio, de patrimonio cultural valenciano introducida en virtud de la Ley 5/2007, de 9 de febrero, que permitió bajo algunas condiciones las reconstrucciones. La Consejería de Cultura y Deporte de la Generalidad adoptó entonces una resolución que autorizaba la compatibilidad de las obras del teatro de Sagunto con la nueva ley. El gobierno valenciano con fundamento en la misma solicitó de la Sala de lo ContenciosoAdministrativo del Tribunal Superior de Justicia de Valencia, órgano competente para la ejecución de la sentencia por haber conocido del asunto en instancia, que fuese declarada la imposibilidad legal y material de ejecutar la sentencia que está prevista en el artículo 105 de la Ley de la jurisdicción contencioso-administrativa. El tribunal apreció la imposibilidad legal de ejecutar la sentencia pues en ejecución del auto se podría demoler el teatro y al día siguiente, como consecuencia del cambio legislativo, levantarse exactamente igual sin que fuese contrario a Derecho. El Tribunal Supremo confirmó esta decisión mediante auto de 29 de octubre de 2009.

\section{LAS OBRAS DE AMPLIACIÓN DEL MUSEO DEL PRADO}

Llegados a este punto de nuestro trabajo resulta oportuno referirse a las sentencias de la Sala de lo Contencioso-Administrativo del Tribunal Supremo de 18 de diciembre de 2002 a las que se hizo referencia al comienzo y que resolvieron acerca del recurso contencioso-administrativo interpuesto por un particular y por la asociación de vecinos del barrio de los Jerónimos contra un acuerdo del Consejo de Ministros de 2 de octubre de 1998, por el que se había autorizado la ejecución de los proyectos de ampliación y rehabilitación del Casón del Buen Retiro y actuaciones en el claustro y parte del atrio adyacentes a la iglesia de San Jerónimo el Real.

El proyecto al que se refieren estas sentencias actuaba sobre el claustro y parte del atrio adyacentes a la iglesia de San Jerónimo el Real de Madrid. Las mismas fueron dictadas poco después de la del teatro Romano de Sagunto y sirvieron para aquilatar durante los dificultosos trámites relativos a su ejecución la doctrina sentada por esta primera.

En esta ocasión la Sala Tercera del Tribunal Supremo pudo abordar el examen de la cuestión en su totalidad y no como en el asunto del teatro Romano como tribunal de casación que resuelve un recurso extraordinario con facultades limitadas a la revisión de una sentencia dictada por otro tribunal inferior.

Las obras de ampliación del museo del Prado consistian en la construcción de edificios nuevos alrededor de los espacios ocupados por los restos del antiguo claustro de los Jerónimos y parte del atrio adyacente de la iglesia de San Jerónimo el Real. El claustro contiguo al templo parroquial de San Jerónimo el Real fue declarado monumento arquitectónico-artístico por la Real Orden de Instrucción Pública 


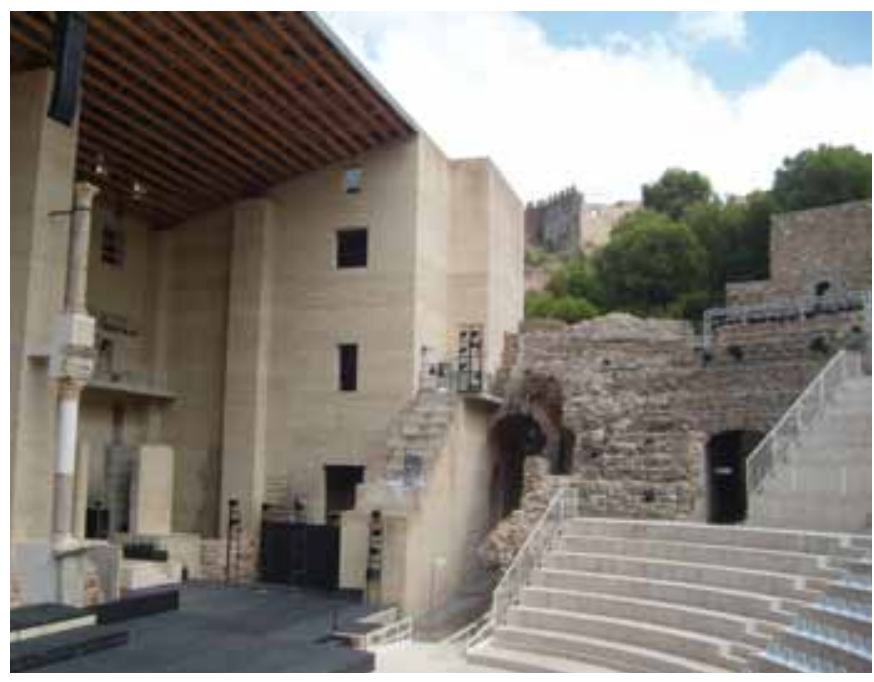

En 2009, en respuesta a la solicitud del gobierno valenciano, el TS confirmó la imposibilidad de ejecutar la sentencia que condenaba a la demolición de las obras del teatro de Sagunto, ya que podría ser demolido y al día siguiente, como consecuencia del cambio legislativo, levantarse exactamente igual sin que fuese contrario a Derecho. Fotos: Sergio Geijo

15 de junio de 1925 (Gaceta del día 20 de julio). De acuerdo con la Disposición adicional 1 1a de la Ley 16/1985, de 15 de junio, del patrimonio histórico español tiene hoy la consideración y la protección que corresponde a los bienes de interés cultural.

Aparte de otras cuestiones juridicas que fueron tratadas en el pleito pero que exceden del asunto al que se refiere el presente artículo, la sentencia parte de la constatación de que según el informe de la Academia de Bellas Artes de San Fernando de 3 de diciembre de 2001 el denominado claustro de los Jerónimos es en realidad el patio subsistente del antiguo claustro principal del Monasterio de los Jerónimos, hoy desaparecido. Sus valores artísticos y arquitectónicos se mantienen actualmente en las arcadas de las cuatro pandas que lo delimitan, pudiendo apreciarse desde el espacio interior del mismo. Se constató que se había realizado una obra de consolidación de esta arquería del antiguo claustro, que se encontraba en una situación de deterioro o degradación visible. La actuación consistió en desmontar la arquería en que consiste hoy el bien de interés cultural, restaurarla y reponerla en una composición idéntica a la que presentaba antes de su desmontaje dentro de un nuevo edificio en forma de cubo destinado a museo.

Expuesto el alcance de las obras proyectadas y de los bienes que eran objeto de protección, las sentencias de 18 de diciembre de 2002 precisaron la doctrina de la sentencia del teatro de Sagunto aclarando con carácter general que los bienes de interés cultural no son intangibles, "contra todos y contra todo", porque eso iría en contra de su conservación.

Asimismo, la sentencia recuerda que el artículo 36 de la LPHE establece la obligación de conservación de los bienes que integran el patrimonio histórico español y declara que la utilización de los bienes de interés cultural quedará subordinada a que no se pongan en peligro los valores que aconsejan su conservación.

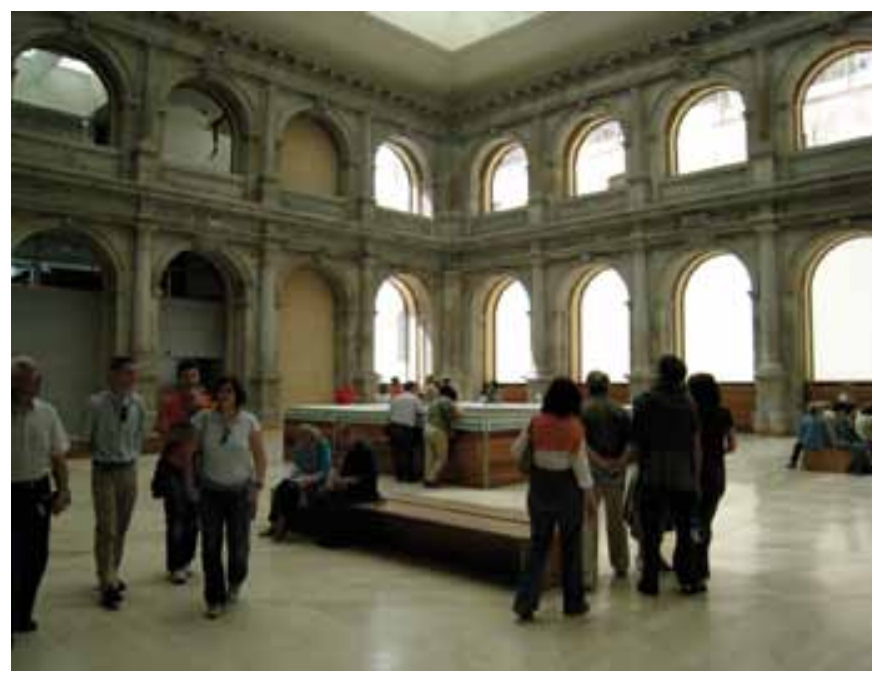

El claustro contiguo al templo parroquial de San Jerónimo el Real se encontraba en una situación de deterioro o degradación visible. La actuación consistió en desmontar la arquería en que consiste hoy el bien de interés cultural, restaurarla y reponerla en una composición idéntica a la que presentaba antes de su desmontaje dentro de un nuevo edificio en forma de cubo destinado a museo. Foto: Fernando García

Como norma esencial aplica el artículo 19.3 de la LPHE que prohíbe toda construcción que altere el carácter de los inmuebles a que hace referencia este artículo o perturbe su contemplación. Dicha norma debe interpretarse en forma conjunta con el artículo 39.2 de la misma ley, expuesto al comienzo de este artículo.

La sentencia del museo del Prado se refiere a la interpretación que del artículo 39. 2 hizo la del teatro Romano de Sagunto señalando que establece el límite positivo de que las intervenciones en los inmuebles vayan dirigidas a su conservación, consolidación y rehabilitación así como otro límite negativo que radica en evitar su reconstrucción, aunque con la excepción de que se utilicen partes originales de los monumentos y pueda probarse su autenticidad. La sentencia afirma que el precepto se debe interpretar de acuerdo con el artículo 11 del Convenio de Granada de 3 de octubre de 1985, para la Salvaguardia del Patrimonio Arquitectónico de Europa en vigor para España, que forma parte de su ordenamiento y que establece la obligación de fomentar tanto el uso de los bienes de interés cultural con arreglo a las necesidades de la vida contemporánea como la adaptación, cuando convenga, de los edificios antiguos para nuevos usos.

El Tribunal Supremo consideró al fin que la obra respeta los límites positivos de su conservación y rehabilitación ya que viene a rehabilitar integramente el claustro y a conservarlo integrado en un edificio que lo rodea, quedando garantizada la contemplación del monumento.

\section{Bibliografía}

MUÑOZ MACHADO, S. (2010) La resurrección de las ruinas (2. Ed. revisada y ampliada). Madrid: IUSTEL, 2010 